\title{
Why Populism? Why Now? An Introduction
}

On behalf of the engaged and insightful Editorial Board, the remarkable staff at Brill, and myself as Managing Editor, welcome to this first issue of Populism, a new journal published by Brill.

As Managing Editor, I appreciate this opportunity to discuss the journal's genesis and its vision - to articulate its goals and its purpose as we grow and develop what we hope will be a central resource on one of the most significant issues influencing political, social and economic life today: populism.

Populism is an international academic journal, grounded in the social sciences but addressing a phenomenon that is as much cultural as it is economic, ideological, social or psychological. Moreover, populism is a local, national, transnational and global phenomenon as well. We seek to understand and analyze populism wherever it occurs, in whatever context it appears.

Populism is grounded on the sense that we-all of us living in contemporary society - are in a noteworthy, and perhaps crucial, moment in human history. Where once it was possible for scholars like Francis Fukuyama to imagine that history-defined as the contest between liberal, capitalist democracy and other forms of social organization — had come to its "end," or where it was once possible for a political commentator like Thomas Friedman to imagine that the world had grown "flat" as the rising tide of globalization lifted all boats into a prosperous, free future, such imaginaries no longer seem credible. History found a way to matter, after all, whether in the rise of political challenges to liberal democracy like that posed by al-Qaeda and similar organizations, or in the near-collapse of the capitalist economy after the US housing crisis in 2008. Subsequent global population shifts in response to economic crisis, climate change, political chaos, and war have intensified nascent or formerly repressed tensions in communities across the world.

One response to these varied economic, social, environmental, and political pressures has been the emergence, or re-emergence, of populism in many societies around the globe. Beset by seemingly intractable problems and embedded in political systems in which leaders have offered few if any solutions to contemporary challenges such as deindustrialization, the diminishing of the value of blue-collar labor, and increased intercultural exchanges as populations shift across the world, significant numbers of people worldwide have seemingly decided that elites of some form or another are the cause of society's 
ills, rather than cures for it. Elites - who, it should be said, have often benefited from the economic and social changes associated with such phenomena as economic globalization-are thus seen not only to have failed to solve the problems "the people" face, but to have actively worked to promote conditions that favor elites at "the people's" expense. Hence an early impulse of all populist movements is blame assignment such that some elites (variously defined) are understood to have worked to harm the people to the benefit of the elite.

Of course, there is more to the sense of elite harm of "the people" than explicit corruption- that "they" are taking what ought to be "ours." There is also the growing sense that what "we" as "the people" want is no longer taken all that much into consideration as elites make their decisions about how the world works. It is one of the features of the administrative state, after all, that it uses experts to manage various programs implemented across public life: The decision whether prescription drugs are safe, or the food supply is safe, or the water supply is safe, or what the best method is to land people on the moon and return them safely to earth is inevitably based on highly technical, complex information that is beyond the ability of most citizens to interpret meaningfully, much less to collect. Accordingly, as government programs proliferate to ensure safe drugs and food and water, to land people on the moon, and to do everything else it is that government does these days, "the people" necessarily cede more and more of their democratic power to shape society as they wish to the regulatory authority of the administrative state. As communities have decided they don't want to set water safety standards by popular vote, they have allowed bureaucrats to set them instead. Ordinary citizens just pay the bill and are supposed to be grateful for the privilege of clean water even if they don't know how that water came out of their taps. A connection between "regular" citizen and elite state decision-makers is, consequently, broken.

What is true at the national level is all the truer at the level of supranational politics. Bodies like the European Union, the World Trade Organization and even the International Criminal Court at the Hague make decisions for technical reasons that are both inaccessible and unresponsive to mass opinion. International financial institutions like the International Monetary Fund and the World Bank impose restrictions and demands on entire societies that they neither represent nor feel any political kinship towards. Nor, for that matter, do the officials in these organizations likely live in the countries their decisions affect, nor do they have friends and families who are likely to suffer as a consequence of their imposition of austerity or structural adjustment programs on various countries. It is literally true, therefore, that for many people around the world the circumstances that dominate their lives are in no way the result of their choosing. Many people, even those living in what we would recognize 
as democratic political systems, are effectively powerless in the face of technocratic, scientific, financial and other constraints imposed upon them.

The 2018 World Report from Human Rights Watch emphasizes this global presence - and global confoundedness - of contemporary populism. The report notes that "Real issues lie behind the surge of populism in many parts of the world":

Economic dislocation and inequality caused by globalization, automation, and technological change; feared cultural shifts as the ease of transportation and communication fuels migration from war, repression, poverty, and climate change; societal divisions between cosmopolitan elites who welcome and benefit from many of these changes and those who feel their lives have become more precarious; and the traumatic drumbeat of terrorist attacks that demagogues use to fuel xenophobia and Islamophobia. ${ }^{1}$

However, as HRW director Kenneth Roth continues:

Populists tend to respond less by proposing genuine solutions than by scapegoating vulnerable minorities and disfavored segments of society. The result has been a frontal assault on the values of inclusivity, tolerance, and respect that lie at the heart of human rights. Indeed, certain populists seem to relish breaking the taboos that embody these values. Invoking their self-serving interpretation of the majority's desires, these populists seek to replace democratic rule-elected government limited by rights and the rule of law-with unfettered majoritarianism. ${ }^{2}$

Human Rights Watch then goes on to detail concerns about abuses of rights, including those abuses grounded in populist sentiments in over go countries varying from Trumpism in the United States to Brexit and challenges to the European Union to the Rohingya Muslims in Burma, and many, many more.

From the simple assertion that "they" are hurting "us," then, populism blooms in multiple dimensions and processes. This diversity compels openness in inquiry as well. As the journal's home page says so well:

1 Kenneth Roth, "The Pushback Against the Populist Challenge," https://www.hrw.org/sites/ default/files/world_report_download/201801world_report_web.pdf, accessed 19 April 2018.

2 Ibid. 
Some researchers prefer to approach populism as an ideology; others consider it as a mode of expression, a discursive style, a species of rhetoric, a political style, a type of political logic, or an exclusionary form of identity politics. Still others eschew such ideational and discursive approaches in favor of more policy-centered and organizational perspectives on populism as a political strategy, a strategy of political organization, or a political project of mobilization that also includes social movements. Put in an even more general framework, populism has also been referred to as a dimension of political culture. Although these different approaches are not necessarily mutually exclusive, they can be usefully associated with three distinct research paradigms identified by Gidron and Bonikowski (2013): (1) populism as political ideology; (2) populism as political style; and (3) populism as political strategy.

The journal Populism is grounded on the recognition that populism has long been with us. Indeed, it is with us now. Populism is culturally and historically contingent. It is historically and culturally embedded. It is also flexible and dynamic and suffuses contemporary political and social life in many manifestations. There is no reason to assume it is going to go away any time soon. As a consequence, this journal came into existence as a platform for examining this endlessly variegated, endlessly fascinating subject.

\section{Our Goals and Commitments}

Initiating a new journal provides the founding Board, press and Managing Editor the opportunity to offer an explicit statement of the principles and goals that will guide the journal's activities. As the journal's website notes, populist currents have characterized many of the most pivotal events and developments in human history-often in times when established institutions lose their normative influence over individual and collective behavior. Aiming to serve as the premier forum for transdisciplinary research, the journal seeks to foster reflection on populism as one powerful way in which societies respond to rapid change in the social order.

Populism seeks to publish the best research about the phenomenon of populism from a wide variety of methods, approaches, and foci. This can, of course, include work easily understood as emerging from a social science perspective: e.g., survey analysis, social movement research, ideological analysis and interpretation, history and development, and the like. But there is no reason to 
suppose that populism only manifests in ways amenable to "traditional" social science research, nor is there any reason to suppose that populism matters to people and to societies only in ways that the social sciences tend to examine. For example, it may well be that a populist movement engenders new musical or other artistic forms that link history and ideology and economic self-interest (among other factors) into powerful formations that shape any populist action or ideology. Such forms are also of interest here since they are part of the milieu of populism.

Populism is also interested in what might be termed "think pieces," or papers that provide a foundation for additional research and insight. Such pieces might succinctly summarize existing knowledge in a new way or glean extant literature to offer insights into likely fruitful areas of academic attention or of missed social consequences. In any case, such work can be expected to stimulate academic conversations about populism and so stand as works of interest to the journal.

The journal also intends to be a resource for those seeking to remain current on the literature on populism. It will publish top-notch reviews of important works in the field, and may, in time, promote exchanges among authors working in shared areas of interest either in mutual reviews or discussion fora. Populism is as a consequence interested in publishing multi-work, thematic reviews, not just assessments of single works.

Moving forward, we aim to:

- Be a central resource for all scholars and citizens interested in populism in any of its many dimensions, whether historical or current;

- Recognize and promote scholarship that explores the social, political, cultural, ideological and economic dimensions of populism;

- Publish contributions that discuss the impact of globalization on the transformation of the conventional ideological landscape in general and on populism in particular;

- Reflect the highest standards of research whatever the methodological techniques that research employs. The question under study drives research methodology; research methodology does not determine the quality of research;

- Provide a space for vigorous exploration of ideas, perspectives, insights and challenges, all in an open and respectful environment;

- Embody the truth that populism is and remains a global phenomenon, deserving analysis wherever it arises;

- Offer the highest levels of integrity and service to both authors and audience. 
My own interest and engagement with populism reflects the belief in the significance of populism as a phenomenon, as well as of its ability to disrupt and remake existing social orders. Notably, I had no idea I was about to be interested in populism when my moment of engagement occurred; rather, as has happened at many other points in my career, my interest in populism arose by serendipitous accident - an accident that also exposed me to a less-traveled side of populist research in the United States. In August 1992, I moved from Huntsville, AL to Spokane, WA, leaving one stint as a non-tenure-track faculty for another. Shortly after establishing residence in Spokane, an event occurred that would become a founding moment in the right-wing militia movement in the United States in the 1990s: the standoff between the FBI and the Randy Weaver family living in a remote, off-the-grid cabin on Ruby Ridge, ID, in the northern panhandle region of that state.

While the basic facts of the Weaver standoff are fairly well known, a brief restatement of them can be useful if only to expose the way I grew to care about right-wing populism in the United States (as opposed to the more commonly studied pattern of left-wing American populism). Randy Weaver and his wife, Vicki, were practitioners of Christian Identity, a racist form of Christianity that holds that white people are the true chosen of God who will eventually enter Paradise after the Second Coming. Originally from Iowa, they moved first to Montana and then to Idaho to escape what they believed would be a coming race war as society fell apart.

While in Idaho, Randy Weaver began to attend meetings of Richard Butler's Aryan Nations, which was headquartered in nearby Hayden Lake, ID. Weaver's racism strengthened, and he adopted the idea that the federal government was an agent of Satan, controlled by a Shadow Government of Jewish people and other "non-whites" planning to destroy the freedom of "real" white people. He also met a man who convinced Weaver to sell two shotguns that had been illegally shortened. Unfortunately for Weaver, that man was a federal informant who reported the sale. Weaver was eventually arrested for the illegal weapons sale.

What became the Siege at Ruby Ridge really started when Weaver missed his court date for his trial. (He claims he was given the wrong date.) US Marshals and agents of the Bureau of Alcohol, Tobacco and Firearms put Weaver under surveillance to assess whether they could safely arrest him for failing to appear in court. However, as the Weavers remained on their isolated property, and remained heavily armed at all times, the Marshals determined that little could be done to capture Weaver. He was, in effect, imprisoned on his own land. 
On August 21, 1992, a group of US Marshals set up a fairly routine surveillance of the Weavers' compound. When they concluded their observations, they began to walk down the hill from which they had been surveilling the Weaver family. At that same moment, Randy Weaver, his son Sammy, and a family friend, Kevin Harris, left the family residence with the Weaver's dog, Striker. Striker bolted down the hill as if chasing something; Sammy Weaver and Kevin Harris gave chase. Randy Weaver followed down the cabin's long access road.

As the Marshals retreated, they came to an open field on the side of the hill. Initially, the agents attempted to hide from their pursuers, but as the dog and his handlers came closer, a US Marshal stepped out of his hiding spot, either did or did not identify himself as a US Marshal, and then shot Striker. An exchange of gunfire ensued. US Marshal William Deagan was killed. So was Sammy Weaver. The Siege at Ruby Ridge had turned violent.

Events escalated rapidly after Marshal Deagan's death. (No government agency knew Sammy Weaver was dead as the situation intensified.) The FBI's Hostage Rescue Team (HRT) deployed to Ruby Ridge; the FBI's regular rules of engagement regarding the use of deadly force were altered to allow any agent to shoot any armed adult whether that adult was threatening an agent or a civilian or not (as the standard rules required); and an FBI sniper fired at Randy Weaver and his friend Kevin Harris when they left the cabin. The sniper, however, missed Weaver but killed his wife Vicki and seriously wounded Harris. (As with the death of Sammy Weaver, no FBI agents yet knew Vicki Weaver was dead.) The access road to the Weaver cabin subsequently became Ground Zero for the staging of both government forces aimed at bringing Randy Weaver in, and as a rallying point for a strident group of protesters demanding that those same federal agents leave the area immediately.

This was the context in which I first became aware of the Weaver standoff. At the time, of course, I knew nothing about any of the Weaver family's background. All I knew was an outline of the charges he was facing and the government-framed narrative of events on Ruby Ridge itself. However, as Spokane is the media hub for that region of the United States, there was extensive coverage of the incident and the various responses to it.

My interest in populism was stimulated in this moment by a practical but indirect question I kept asking myself as the Ruby Ridge incident unfolded over eleven days. This was some version of, "Why do all these local people seem to like Randy Weaver so much?" After all, whether it was his racist religious values or the fact that he had allegedly violated federal law and then refused to answer a court date, Weaver hardly seemed an admirable person. Why, then, would so many people in northern Idaho and eastern Washington respond to his story and be willing to take time and risk police sanction? 
This question was deepened by my immediate experiences just before moving to Spokane. I had quite literally just moved to Spokane, WA from Huntsville, AL in the few weeks preceding this event. The politics and culture of Huntsville, it turns out, are not like the politics and culture of a lot of the rest of Alabama, at least in terms of whether or not the people of Huntsville like and trust the federal government. Alabama, of course, has a notorious history of resisting civil rights, school integration, and other federal programs aimed at changing established laws in the state. Huntsville, however, is a federal town. One of NASA's three operations centers, the Marshall Space Flight Center, is in Huntsville. (The other two are in Houston, TX and Cape Canaveral, FL). The Saturn $\mathrm{V}$ rocket engines that carried astronauts to the moon were tested in Huntsville. You can still see the test stands if you take a tour of Marshall Space Flight Center, a complex which occupies part of the U.S. Army's Redstone Arsenal, the base where the Army undertakes its own missile development and testing programs. In addition, Huntsville named its civic center complex the Von Braun Civic Center. The von Braun in question is Wernher von Braun who, prior to moving to the United States after World War II and leading the U.S. missile design effort for the space race, led the V-2 rocket program for the Nazi Germans. Unsurprisingly, there is no von Braun memorial in London, but in the federal town of Huntsville, von Braun can be a hero for his post-war activities.

To leave such a pro-federal environment only to enter a world so explicitly hostile to federal actions made me something of a stranger in a strange land. And it wasn't only the protesters at the entry road to the Weaver compound who expressed anti-federal government values. Such sentiments were common on the streets of Spokane, confirmed in newspaper and television "man-on-thestreet" interviews. Something was very different in the nation's Northwest, at least compared to one urban, technologically supercharged town in Alabama.

In time, after the 1990s militia movement had developed in response to Ruby Ridge, the fire at the Branch Davidian compound in Waco, Texas (just eight months after Ruby Ridge), and the destruction of the Murrah federal office building in Oklahoma City, OK in 1995, I published Rage on the Right: The American Militia Movement from Ruby Ridge to Homeland Security (Rowman and Littlefield, 2002), in part to answer that lingering question: Why did so many Americans support Randy Weaver (and people like him) despite what seemed to me to be his utterly offensive values and lifestyle. Part of my answer, informed by my understanding of populist principles and actions, was that the reaction to support Weaver had nothing to do with Weaver at all. Rather, at least some of the pro-Weaver activism was a means through which many Westerners voiced their belief that the federal government had grown too 
abusive of its powers and prerogatives. These protests also provided Weaver sympathizers (and many others) a way to build identity connections among like-minded people who likely would never otherwise have found each other. The Weaver moment, then, was a founding populist outcry of a broader movement that reshaped American politics in the 1990s.

Notably, although the movement declined in the later 1990s, partly as a result of the destruction of the Murrah building but also as a result of its successes in influencing federal policy through its presence in the Republican party, the right-wing populist movement that took off after the Ruby Ridge standoff never disappeared entirely. The Tea Party movement during the Obama presidency manifested many populist themes as it pushed through the US political system, of course, and the campaign and subsequent election of Donald Trump to the White House in 2016 saw the elevation of a rhetorical populist to the Presidency of the United States. In turn, Trump's campaign and victory seem to have empowered anti-immigrant, racist and ethnic bigots to express their values and goals openly and vigorously. Right-wing populism may have declined in the United States after 2000, but it did not go away. As the author William Faulkner noted in his novel, Requiem for a Nun: "The past is never dead. It's not even past."

\section{In This Issue}

We are excited that this first edition of Populism offers four pieces that represent the range and scope that the journal seeks to bring to our collective attention. In their paper "On Populism and Nationalism," for example, Federico Finchelstein and Nadia Urbinati offer a thoughtful interpretation of populism not as a concept, but as a force and factor in global history. They trace the relationship populism has with both constitutional democracy and dictatorship, assessing the ways populism informs and engages these seemingly opposed political regime types. In particular, they explore the ways in which populist governments attempt to remake democratic systems with an emphasis on majority power in the name of "the people."

Meanwhile, in "Populism in Power: Between Inclusion and Autocracy," Carlos de la Torre and Enrique Peruzzotti offer a careful look at populism in Latin America. Latin America, after all, is both the locus of the first modern populist government - that of Juan Perón in Argentina—and is the region with the most extensive and extended experience of populist regimes, such as the Chavez government in Venezuela. Their article explores the differences between older and more recent experiences of populism in Latin America and 
carefully analyzes the relationships between populism and authoritarianism. It also offers insights into how the Latin American experience of populism might inform analysis of populism wherever it arises.

Alberto Martinelli examines the ways in which the populist and nationalist waves that seem to be sweeping across Europe are symptoms of a deeper challenge to the legitimacy and stability of the European Union. Nationalism and populism are seen to be in a process of merging as a nationalist populist alternative to the unity and transnationalism of the European Union. Finally, Martinelli describes possible paths for strengthening the EU project while avoiding falling prey to the ills of either nationalism or populism.

This first edition of Populism also contains the first of the discussions, or think pieces, that we expect to be a regular part of the journal's offerings. Lawrence Rosenthal, in "Othering' Nationalism: The Bookends of the Industrial Age," offers an explicit linkage of the Donald Trump presidency (and movement) with the regime of Benito Mussolini in the 1920 and 1930s, asking, as many commentators have worried, whether a fascist movement is "stalking" America. He explores the conditions that have promoted the rise of fascist and populist regimes and connects them to both existing and emerging social and political conditions in the United States. The paper is sure to stimulate many questions, much debate, and continuing research in the area.

We believe this first edition reflects Populism's broad agenda: It has articles examining populism in multiple regions and as an idea in itself. It offers new conceptualizations of populism's appeal and effect in a global context. And it stimulates new questions and new perspectives on the interlacing of history and experience in contemporary contexts. We are excited to bring it to you.

\section{4}

\section{Thank You}

No project as complex as launching a new journal could possibly be the work of just one person. I want to take a few moments to thank both the staff at Brill and the Editorial Board for their support and insight in bringing this journal into being.

At Brill, Acquisitions Editor Jason Prevost has been central to making this journal happen. His colleagues, Evelien van der Veer, Jennifer Obdam, Kristen Chevalier and the support staff have been exceptionally helpful in assisting me in navigating the process of editing the journal. This has been an exciting but daunting journey made much, much easier because of their openness and enthusiasm. 
Likewise, the internationally renowned, multidisciplinary Editorial Board has been both generous and insightful to work with as this journal has moved from idea to proposal to being situated in a home press to, finally, the journal you see today. Each Board member deserves special thanks for their contributions and ongoing efforts.

- Mehdi P. Amineh, Amsterdam Institute for Social Science ResearchUniversity of Amsterdam and International Institute for Asian StudiesLeiden University

- Vincenzo Cicchelli, Gemass, Université Paris-Sorbonne/CNRS and University Paris Descartes

- Carlos de la Torre, University of Kentucky

- Paula Diehl, Humboldt-Universität zu Berlin

- David Fasenfest, Wayne State University

- Federico Finchelstein, The New School for Social Research

- Paul James, Western Sydney University

- Devin K. Joshi, Singapore Management University

- Lauren Langman, Loyola University Chicago

- Alberto Martinelli, University of Milan

- Danielle Resnick, International Food Policy Research Institute (IFPRI)

- Amy Skonieczny, San Francisco State University

- Ben Stanley, swPs Uniwersytet Humanistycznospołeczny

- Manfred B. Steger, University of Hawai'i at Mānoa

- Nadia Urbinati, Columbia University

- Amentahru Wahlrab, The University of Texas at Tyler*

* Book Review Editor.

This remarkable group of internationally and professionally diverse experts is an extraordinary asset to the journal, and they have my thanks for their help so far as well as for their support in the future as we build Populism into the resource we know it is destined to be.

\section{Lane Crothers}

Managing Editor

alcroth@ilstu.edu 